\title{
The bone microenvironment promotes tumor growth and tissue perfusion compared with striated muscle in a preclinical model of prostate cancer in vivo
}

Haider Mussawy ${ }^{1 *+}$ (D) Lennart Viezens ${ }^{2+}$, Malte Schroeder $^{1,3}$, Svenja Hettenhausen $^{1}$, Jördis Sündermann ${ }^{1}$, Jasmin Wellbrock ${ }^{4}$, Kai Kossow ${ }^{5}$ and Christian Schaefer ${ }^{1,3}$

\begin{abstract}
Background: Prostate cancer-related morbidity is associated with its preferential spread to the bone. Although the molecular interactions between the bone microenvironment and cancer cells have been researched extensively, the relevance of the microvascular properties of prostate cancer bone metastases remains largely unknown. Most preclinical studies focusing on microvascular analyses are based on heterotopic tumor implantation, whereas the impact of the microenvironment on site-specific growth behavior and angiogenesis is rarely addressed.

Methods: The microvascular changes associated with tumor growth in bone and soft tissue were characterized by implanting single cell suspensions of LnCap, Du145, and Pc3 cells into the femur (femur window) or striated muscle (dorsal skinfold chamber) of NSG mice. Tumor growth and the local microvasculature were analyzed for 21 days using intravital fluorescence microscopy.

Results: The results showed a higher engraftment of tumor cells in bone than in striated muscle associated with accelerated growth of LnCap cells and Pc3 cells. Permeability, blood flow, and tissue perfusion rates were greater in bone than in striated muscle. Du145 cells showed similar growth behavior in both tissues with similar vascular properties. The bone microenvironment facilitated tumor engraftment and growth. Increased microvascular density in striated muscle led to a higher tumor burden during early growth, whereas the increased perfusion promoted later prostate cancer growth in bone.
\end{abstract}

Conclusions: Monitoring prostate cancer microcirculation in bone and soft tissue may be useful to evaluate the organ-specific efficacy of new treatments.

Keywords: Bone microenvironment, Femur window, Dorsal skinfold chamber, Tumor growth, Prostate cancer, Intravital microscopy

\section{Background}

Prostate cancer is the most common cancer in men and the sixth leading cause of cancer-related death among men worldwide [1]. It originates in soft tissues and is a relatively slow-growing tumor; however, it has a high probability of forming metastases in the skeleton, which

\footnotetext{
* Correspondence: h.mussawy@uke.de

${ }^{+}$Haider Mussawy and Lennart Viezens contributed equally to this work

${ }^{1}$ Department of Orthopaedic Surgery, University Medical Center

Hamburg-Eppendorf, 20246 Hamburg, Germany

Full list of author information is available at the end of the article
}

results in significant disease morbidity and mortality including intractable bone pain and pathological fractures. Bone tissue is the preferred metastatic site and provides a supportive microenvironment where prostate cancer cells can reside and grow [2]. Despite the known impact of the local microenvironment and site-specific microvascular properties on tumor progression, relatively little is known about the microcirculation of bone metastases [3, 4]. This can be largely attributed to the limited availability of suitable preclinical models [5], especially the difficulties in generating mouse models of bone metastasis [6], and

(c) The Author(s). 2018 Open Access This article is distributed under the terms of the Creative Commons Attribution 4.0 International License (http://creativecommons.org/licenses/by/4.0/), which permits unrestricted use, distribution, and reproduction in any medium, provided you give appropriate credit to the original author(s) and the source, provide a link to the Creative Commons license, and indicate if changes were made. The Creative Commons Public Domain Dedication waiver (http://creativecommons.org/publicdomain/zero/1.0/) applies to the data made available in this article, unless otherwise stated. 
limitations associated with imaging of bone tissue at a high spatial resolution [7]. Heterotopic tumor implantation in soft tissues is commonly used to characterize tumor microcirculation, growth, and susceptibility to anti-angiogenic therapies; however, the influence of the host tissue microenvironment on tumor characteristics is rarely addressed [3, 6, 8-13].

Hence, we developed a bone tumor model that allows the continuous observation of tumor microvascular properties and growth in vivo, and described morphological angiogenic alterations during tumor growth in bone [7, 14-16].

To determine the effect of the microvasculature of prostate cancer growing in bone and striated muscle on growth behavior, the prostate cancer cell lines LnCap, Du145, and Pc3 were implanted into the femur [femur window (FW)] and striated muscle [dorsal skinfold chamber (DSC)] of non-obese diabetic/severe combined immunodeficiency/y-chain [NOD-Prkds IL2rg (NSG)] mice. After implantation of the cancer cells, the local microcirculation was analyzed for 21 days by intravital fluorescence microscopy to determine the effect of the environment on microvascular properties during tumor growth in bone and in striated muscle.

\section{Methods}

\section{Cell lines}

The prostate cancer cell lines LnCap, Du145, and Pc3 were transfected with the fusion protein mCherry, a derivative of the red fluorescent protein, using Lipofectamine (Invitrogen, Karlsruhe, Germany). Cells with a strong red signal were selected by fluorescence-activated cell sorting (>95\% expression; FACSAriaII, BD Biosciences, Heidelberg, Germany). Cells were grown in D-MEM/F12 medium containing $10 \%$ fetal bovine serum. The cells were cultured at $37{ }^{\circ} \mathrm{C}$ and $5 \% \mathrm{CO}_{2}$ in a humidified incubator. The cell lines PC3 (catalogue number ACC-465), Du-145 (catalogue number ACC-261) and LnCap (catalogue number ACC-256) were authenticated at DSMZ (Deutsche Sammlung von Mikroorganismen und Zellkulturen $\mathrm{GmbH}$ ) during the term of experiments. The cell lines were routinely tested for mycoplasma contamination with MycoAlert Mycoplasma Detection Kit from Lonza.

\section{Tumor model}

Male NSG mice (12-14 weeks old) (University Medical Center Hamburg-Eppendorf, Germany) were used in the study. Animals were kept in a 12:12 h light:dark cycle at $24{ }^{\circ} \mathrm{C}$ and $50 \%$ humidity. Mice were caged individually and had free access to tap water and standard pellet food (Altromin, Lage, Germany). The study was approved by the local governmental animal care committee (protocol number 05/12) and was conducted in accordance with the German legislation on the protection of animals and the National Institutes of Health (NIH) Guidelines for Care and Use of Laboratory Animals (NIH Publication \#85-23 Rev. 1985). All surgical procedures were performed under aseptic conditions while maintaining body temperature at physiological levels using a heating pad (Omnilab PST 100, Jürgens, Germany). Prior to surgical procedures, mice were anesthetized $(7.5 \mathrm{mg}$ of ketamine hydrochloride and $2.5 \mathrm{mg}$ of xylazine/100 $\mathrm{g}$ of body weight), and the skin surrounding the site of the surgical approach was shaved and depilated.

\section{Preparation of the dorsal skinfold chamber}

The microcirculation and tumor growth in striated muscle tissue were analyzed in the DSC. The chamber preparation was described previously in detail [17]. Prior to the final DSC fixation, a suspension of $1 \times 10^{6}$ cells in $1 \mathrm{ml}$ of phosphate buffered saline was centrifuged, and after removing the supernatant, LnCap, Du145, or Pc3 cells were implanted into the striated muscle tissue of NSG mice.

\section{Preparation of the femur window}

The microcirculation and tumor growth in bone were analyzed in the FW. Chamber preparation was described previously in detail [7]. The aseptic surgical conditions and use of heating plates during the operation were as described above. Prior to the final FW fixation, a suspension of $1 \times 10^{6}$ cells in $1 \mathrm{ml}$ of phosphate buffered saline was centrifuged, and after removing the supernatant, LnCap, Du145, or Pc3 cells were implanted into the cancellous bone of the diaphysis of NSG mice.

\section{Experimental protocol}

The animals were randomly divided into six groups $(n=$ 105): three groups had FW implantation and three groups had DSC implantation, each with LnCap, Du145, or Pc3 cells. Each group had 15 FWs or 20 DSCs implanted. Animals without tumor engraftment on day 7 or with clinical signs of postoperative infection were excluded. Mice with excessive tumor growth and with subsequent femur fracture were sacrificed with an overdose of the anesthetic administered via the tail vein. Intravital fluorescence microscopic analysis of tumor growth, vascularization, and effective vascular permeability (PERM) was performed weekly after chamber implantation. At the end of the in vivo experiments, the animals were sacrificed with an overdose of the anesthetic.

\section{Intravital fluorescence microscopy}

To obtain microcirculatory parameters, three locations within the tumor were analyzed (Additional file 1: Figure S1 and Additional file 2: Figure S2) using an intravital fluorescence microscope (Axioplan, Zeiss, Oberkochen, Germany) and a 20× objective (LD Achroplan 20x/0.40, 
Zeiss). The microscope was equipped with fluorescence filter sets for fluorescein isothiocyanate (FITC) and red fluorescence protein, an intensified charge coupled device video camera (C-0377-1, Hamamatsu Photonics, Hamamatsu, Germany), a Photomultiplier Tube (R4632, Hamamatsu Photonics), and a Computer (Apple Power Macintosh, G4, Dual 500 MHz Power PC, 1 GB SDRAM) for digital signal recording and off-line analysis. During measurements, the body temperature was maintained at physiological levels using a heating pad. To eliminate movements of the transparent chamber caused by breathing, the chamber was fixed to the microscope using a custom-made clamp.

\section{Tumor growth and microcirculatory analysis}

Assessment of tumor growth was performed with epi-illumination. Analysis of the tumor area was performed using Axiovison software (Axiovison 4.6, Carl Zeiss Jena GmbH, Jena, Germany; Fig. 1a-f). For contrast enhancement of the microcirculation, $0.1 \mathrm{ml}$ of $5 \%$ FITC-labeled dextran 150,000 (Molecular Probes, Invitrogen Ltd., Paisley, UK) was administered via the tail vein. Fluorescence images were recorded digitally and noncompressed for $10 \mathrm{~s}$, and analyzed off-line using the software package from the NIH (NIH Image 1.62). Functional capillary density (VD), i.e., the length of all perfused microvessels per observation area, was measured and expressed in $\mathrm{cm} / \mathrm{cm}^{2}$. Mean diameters (D), centerline velocity (Vmean), and blood flow rate (BFR) were measured in all perfused microvessels. $\mathrm{D}$ was measured in $\mu \mathrm{m}$ perpendicularly to the vessel path. Vmean was analyzed using $\mathrm{NIH}$ Image 1.62. BFR was calculated using the formula $\mathrm{Q}=\pi \mathrm{x}(\mathrm{d} / 2)^{2} \mathrm{x} \mathrm{v} / 1.6[\mathrm{pl} / \mathrm{s}]$, where 1.6 represents the Baker-Wayland factor [18] to correct for the parabolic velocity profile in microvessels. The tissue perfusion rate (TPR), i.e., blood flow rate per time and area, was obtained using VD and BFR as described previously [19].

\section{Effective vascular permeability}

PERM was measured as described previously [18]. Briefly, after the application of $0.1 \mathrm{ml}$ of $5 \%$ FITC coupled to bovine serum albumin via the tail vein, the fluorescence intensity was measured intermittently for $10 \mathrm{~min}$ and recorded digitally (PowerLab/200 AD Instruments Pty Ltd., Castle Hill, Australia). The permeability value was calculated as $\mathrm{P}=(1-\mathrm{HT}) \mathrm{V} / \mathrm{S}(\mathrm{I} 0$ - Ib) $\mathrm{x} \mathrm{dI} / \mathrm{dt}+1 / \mathrm{K})$, where $\mathrm{I}$ is the average fluorescence intensity of the whole image, IO is the value of I immediately after filling of all vessels by FITC-BSA, and Ib is the background fluorescence intensity. The average hematocrit (HT) of vessels is assumed to be equal to $19 \%$ [20]. V and S are the total volume and surface area of vessels within the tissue volume covered by the surface image. The time constant of BSA plasma clearance $(\mathrm{K})$ is $9.1 \times 10^{3} \mathrm{~s}[21]$.

\section{Statistics}

Differences between the study groups were analyzed with SPSS (IBM SPSS Statistics 19, Chicago, IL, USA) using the one-way repeated measures ANOVA F-test (Greenhouse Geisser adjustment in case of violated assumption of sphericity) between different measurement points. A post-test (Bonferroni) were conducted to determine significance between individual time points once the significance of the overall test was determined. All values are expressed as mean \pm SD. Statistical significance was based on $p$-values $<0.05$.

\section{Results}

Microvascular alterations during prostate cancer growth were analyzed in vivo in striated muscle and in bone using intravital fluorescence microscopic analysis of the DSC and FW of mice implanted with three different cell lines.

\section{Tumor take rate and growth behavior}

The take rate was lower in striated muscle than in bone tissue. Engraftment of LnCap and Du145 cells was equal with $70 \%$ and $93 \%$ in striated muscle and bone, respectively. Similar rate differences were observed in Pc3 cells at $45 \%$ vs. $67 \%$ in striated muscle vs. bone. Tumor size on day 7 was 2 -fold greater in striated muscle than their counterparts in bone (Additional file 3: Table S1 and Fig. 2a). Tumors in both tissues showed significant growth at 7-21 days (Figs. 1 and 2 and Additional file 3: Table S1). The Pc3 cells demonstrated similar trends albeit without achieving statistical significance. Tumors in striated muscles exhibited similar growth from 7 (defined with 100\%) to 21 days without statistically significant differences between cell lines (LnCap, 205\%, $n=12$; Du145, 225\%, $n=$ 10; and Pc3, 210\%, $n=4)$; however, in bone, LnCap- and Pc3-derived tumors showed significant variation in growth behavior, with a nearly quadruplication and triplication time of 14 days in LnCap (382\%) and Pc3 (274\%), respectively. This caused femur fractures in all LnCap mice after day 14, and mice were euthanized in accordance to the study protocol. The rapid growth of Pc3-derived tumors resulted in tumor areas of $730 \%$ on day 21 , with femur fractures occurring thereafter (Figs. 1 and 2b); these mice were euthanized. Du145 cell-derived tumors showed variation in growth rate with a doubling time of 14 days (Du145, 250\%, $n=14$ ) and resulted in increased tumor area of $340 \%$ on day 21 in bone, compared to striated muscle tissue tumors with relative tumor growth of $225 \%$.

\section{Tumor microcirculation depends on the host tissue}

The bone microenvironment was associated with increased microvascular permeability, blood flow, and tissue perfusion in comparison to striated muscle (Fig. $3 a-c, g-i$, and $j-1)$. The functional vascular density was higher in the 

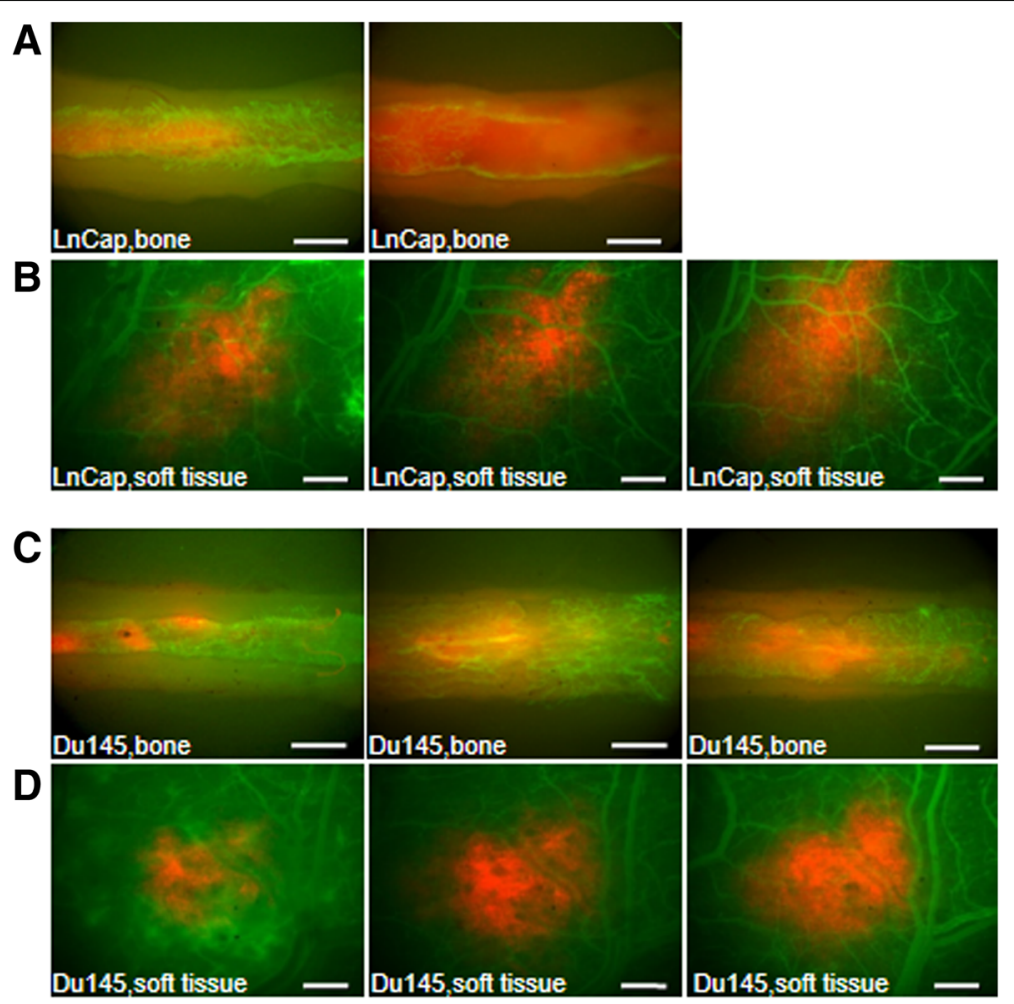

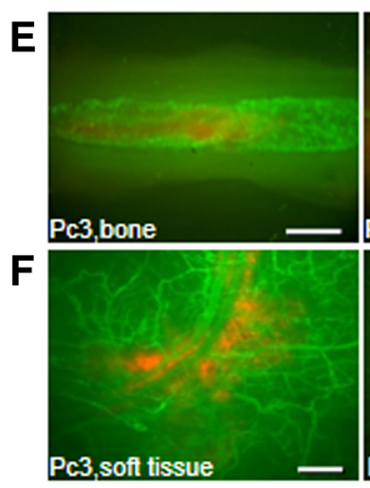

day 7

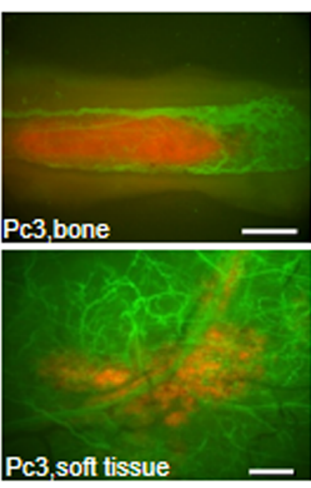

day 14

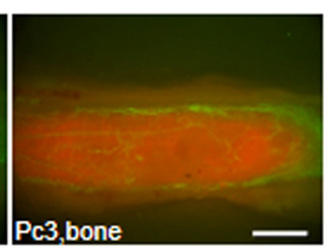

Fig. 1 Intravital fluorescence microscopy of tumor growth and local microvessels in the femur window (a, c, e) with a 2.5x objective and in the dorsal skinfold chamber (b, d, f) with a 1.25x objective after contrast enhancement with $0.1 \mathrm{ml}$ of 5\% FITC-labeled dextran 150,000 on days 7, 14, and 21. Note the different tumor growth rates of $\operatorname{LnCap}(\mathbf{a}, \mathbf{b})$, Du145 (c, d), and Pc3 (e, f) cells (scale bars $\mathbf{a}, \mathbf{c}, \mathbf{e}=500 \mu \mathrm{m} ; \mathbf{b}, \mathbf{d}, \mathbf{f}=680 \mu \mathrm{m})$

DSC than in the FW for LnCap and Du145 tumors on days 7 and 14, whereas the differences did not reach significance for Pc3 tumors because of the small sample size in the DSC (Fig. 3p-r). The Vmean and D values were higher in bone than in striated muscle in all cell lines (Fig. 3d-f and $\mathrm{m}-\mathrm{O}$ ). The Vmean was highest for Du145 cells in bone compared with the other cell line-derived tumors in bone and striated muscle (Fig. 3d-f).

\section{Discussion}

We herein demonstrate the significant impact of the bone and soft tissue microenvironments on prostate cancer growth and tumor microvascular properties in vivo during a period of 21 days by intravital microscopy of the FW and DSC.

\section{Advantages and limitations of the tumor model}

In recent years, many indirect observation methods were developed to analyze tumor growth in bone and the morphological and functional aspects of angiogenesis. Because rodents do not commonly form spontaneous bone metastases, designing a research model is difficult [22]. Xenograft models generated by implantation of human tumor cells into immunodeficient mice considerably 


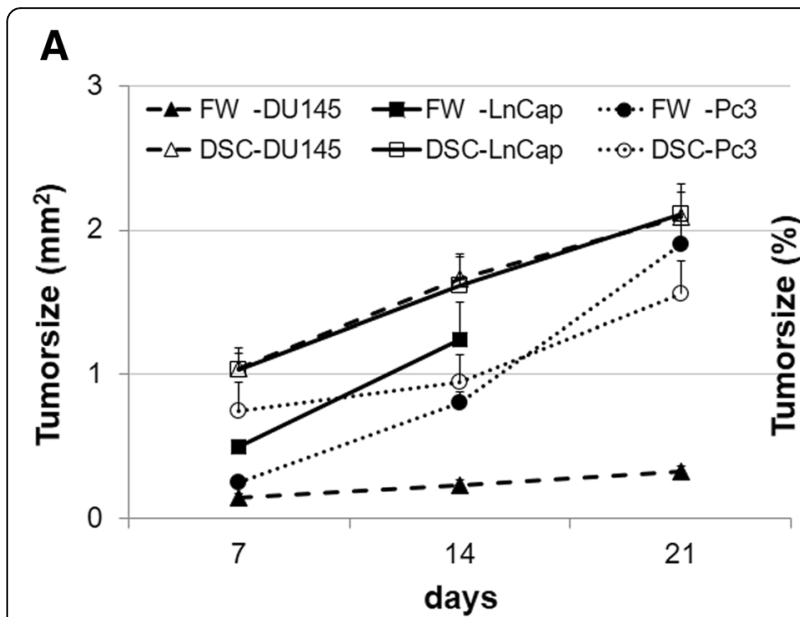

B

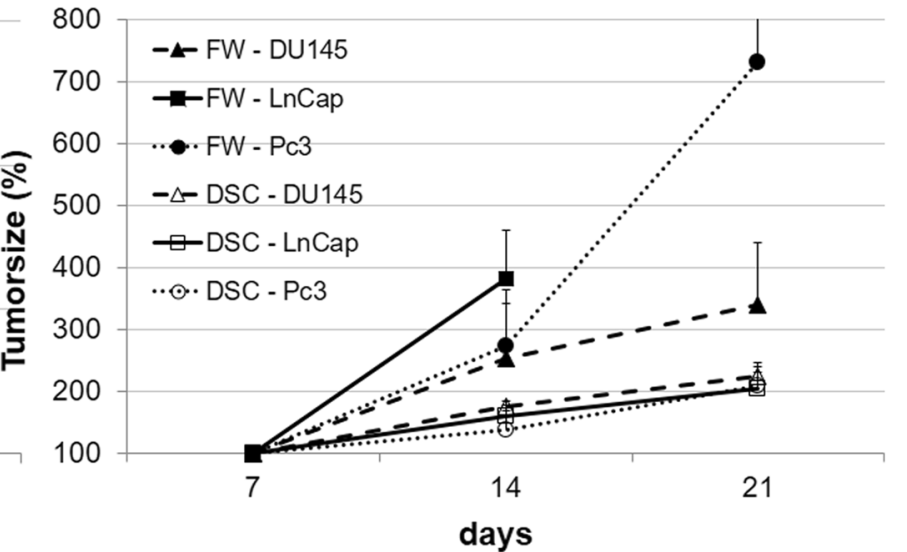

Fig. 2 Tumor growth in the femur window (FW) and dorsal skinfold chamber (DSC) during 21 days as absolute (a) and relative (b) values. The Fig. a shows the significant higher tumor burden of LnCap and Du145 cells in striated muscle than in bone. The tumor burden of Pc3 cells was higher in striated muscle than in bone, although the difference was not statistically significant. In Fig. $\mathbf{b}$ the growth of Pc3 cell-derived tumors was significantly greater in bone than in striated muscle on days 14 and 21. LnCap cells showed greater tumor growth in bone than in striated muscle tissue on day 14 . The growth of Du145 cells showed no significant differences during the observation period

improved our understanding of the tumor microenvironment [23-25]. But the results obtained on immunodeficient mice cannot be directly translated onto the human biology. Experimental metastases are commonly generated by intracardial or intratibial injection of cancer cells to induce bone metastasis [26, 27]. Although intracardial injection mimics the process of metastasis, the site of bone metastases and the time of development cannot be controlled in the study design. Another frequently used procedure is the subcutaneous application of tumor cells and subsequent postmortem evaluation, which is useful for histological examination; however, similar to the previous model, this design does not permit continuous in vivo imaging of functional microvascular alterations during tumor growth [28]. Models that use direct inoculation of tumor cells into bone, as described in this study, mimic the final stages of bone colonization, whereas they do not address the proliferation of primary neoplasm, intravasation into blood vessels, extravasation into bone marrow, tumor cell dormancy, paracrine local tissue and activation of the tumor cells. In addition, the role of intact immune system as controlling the tumor growth can not be analyzed with the presented model [29]. Furthermore, the direct inoculation of a large number of tumor cells may generate a different initial tumor size. The difference in tumor size is a weakness in this study since tumor microcirculation may vary with size of the tumor.

In addition to the difficulties associated with generating bone metastases in rodents within a defined time frame and at a specific growth site, monitoring tumor growth and angiogenesis in bone is difficult. Bauerle et al. investigated bone metastasis in nude rats using magnetic resonance imaging, volumetric computed tomography, and ultrasonography [30]. These technologies can be used to assess tumor growth and detect solid metastases; however, these methods are limited regarding the detection of tumors at the early stages of formation or the visualization of functional microvascular changes associated with tumor growth in vivo in real time [31]. Imaging technologies lack spatial resolution or the ability to monitor morphological and functional aspects of microcirculation during tumor growth. In this context, intravital microscopy using transparent chamber techniques is a successful approach to investigate the microcirculatory properties of various tissues at a high spatial resolution [7, 12, 13, 32-34].

Each model offers advantages and disadvantages, and no single ideal model exists. Intravital fluorescence microscopy provides anatomical and functional insight into tumor pathophysiology, including angiogenesis and the microenvironment in vivo, in a non-invasive and non-destructive manner [4].

Bone tissue increases the take rate in the prostate cancer cell lines LnCap and Pc3 and is associated with reduced early tumor growth

A large body of literature indicates that the tumor microenvironment is crucial for tumor progression and the response to treatment [9]. The host tissue determines tumor cell survival and growth via molecular interactions [35]. Consistent with previous studies, we showed that the microenvironment affected the tumor take rate [36, 37]. The tumor take rate was approximately one third higher in bone tissue than in muscle for all three cell lines despite equal amounts of inoculated tumor cells. The cell lines used were suitable for 

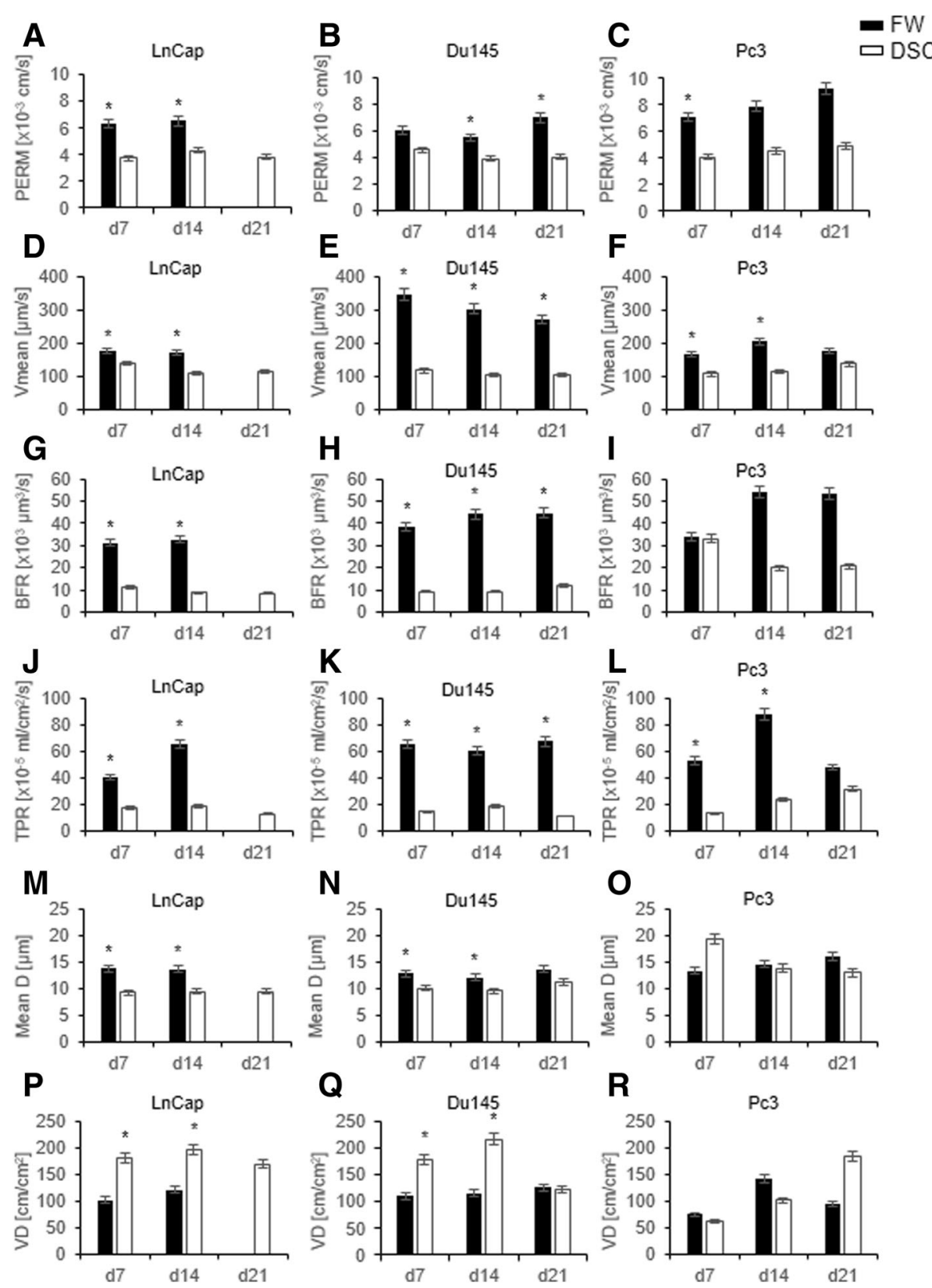

Fig. 3 a-r Microvascular parameters on days 7, 14, and 21 after tumor implantation measured in three regions of interest (two in the border zone and one in the center zone of the tumor) of LnCap, Du145, or Pc3 cells in the dorsal skinfold chamber (DSC) and in the femur window (FW) as assessed by intravital fluorescence microscopy and computer-assisted image analysis. The black bars represent the FW group, and the white bars represent the DSC group. All values are presented as the mean \pm SD. $\left(^{*} p<0.05\right)$. Abbreviations: PERM, effective vascular permeability; Vmean, centerline velocity; BFR, blood perfusion rate; TPR, tissue perfusion rate; Mean D, mean diameter; VD, vessel density

experimental studies of bone metastasis with engraftment rates of over $66 \%$. However, the use of Pc3 cells in xenograft DSC models in NSG mice is limited because of the low engraftment rates in striated muscle.

Despite the higher engraftment rates, the initial tumor size for the three cell lines was nearly $50 \%$ smaller in bone than in muscle on day 7 (Fig. 2a and Additional file 3: Table S1). In addition to paracrine survival factors, which influence take rate, the microcirculation of the host tissue has a major impact on tumor growth because the survival and growth of cells depends on an adequate supply of oxygen and nutrients [38]. Pre-existing host vessels support or limit early tumor growth before angiogenesis [39]. Since the diffusion of oxygen is limited to $150-200 \mu \mathrm{m}$ [40], the higher functional vascular density and consequent decrease in intervascular distance in striated muscle 
may promote early tumor growth compared with that in bone tissue. These observations are in line with the microvascular architecture in the dorsal skinfold chamber that presents the usual striated muscle with regular microvessel anatomy [41]. In contrast, the blood supply in bone is guaranteed by fenestrated capillaries (longitudinal and transverse canals) $[42,43]$. This system, normally allows the intravasation of developing myeloid cells into the blood due to the large pores present [44]. These pores $(30-40 \mu \mathrm{m})$ may facilitate extravasation for tumor cells and therefore support tumor growth in bone.

\section{The microvascular properties of bone substantially promote tumor growth in LnCap and Pc3 tumors}

Analysis of tumor size according to initial tumor area on day 7 demonstrated a pronounced growth rate in LnCap and Pc3 tumors in the bone microenvironment (Fig. 2b). The rapid tumor growth led to femur fractures after 14 days in LnCap and after 21 days in Pc3 mice. Despite the mixed osteolytic/osteoblastic pattern of LnCap tumors compared with the osteolytic growth of Pc3 cells, pathologic fractures were delayed in Pc3 tumors compared with those of LnCap cells [45]. This can be attributed to the difference in absolute tumor size, as the initial tumor burden was $50 \%$ lower in Pc3 tumors on day 7. Tumor growth was markedly lower in Du145 tumors than in those derived from other cell lines and corresponded to their counterparts grown in striated muscle tissue. The slow tumor growth in bone was consistent with previous observations [45].

Tumor growth beyond a few cubic millimeters is angiogenesis-dependent [46]. Angiogenesis is a prerequisite for tumor growth, whereas vessel density is not necessarily accompanied by tissue perfusion, and temporal variation during tumor growth needs to be assessed; therefore, intravital microscopy provides a detailed insight into tumor biology $[34,47,48]$. To determine whether the microvascular properties accounted for the differences in tumor growth between secondary bone and soft tissue tumors, we analyzed the functional and morphological aspects of tumor vessels.

Angiogenesis involves multiple interdependent steps, as described in previous studies [49]. One of the first steps is the degradation of the basement membrane, as indicated by increased PERM $[50,51]$. Due to the vascular architecture in bone the effective vascular permeability was higher in the femur window than in the dorsal skinfold chamber. This may facilitate the first step in angiogenesis. Secondary bone tumors were associated with increased permeability compared with that in striated muscle tissue. This may promote prostate cancer growth in bone and contribute to impaired drug delivery via increased interstitial pressure [52, 53]. Knowledge of local bone vascularization, including PERM, could be essential for preventing the formation of secondary bone tumors in prostate cancer patients [54].

The lower vascular density of bone tumors, in particular LnCap and Du145 tumors, indicated that high vascularity is not necessarily associated with accelerated tumor growth, as microvessel density does not reflect the metabolic demand of a tumor [55]. Furthermore, we showed that, despite the lower vascular density, increased blood flow and vascular diameter resulted in increased tissue perfusion rates in bone tumors. Under physiological conditions, the tissue perfusion rate was similar between bone and striated muscle tissue in NSG mice, as previously demonstrated [56]. The different organ environments differentially affected tumor growth. The higher perfusion rate may have contributed to the accelerated tumor growth of Pc3 and LnCap tumors. The tumor size of Du145 was decreased. This could be associated with paracrine/autocrine mechanisms, which greatly contribute to tumor progression [57]. These paracrine factors may be crucial for the growth characteristics in both tissues. In bone, the osteocytes support cancer progression by cytokines production [58]. Furthermore, the osteoclasts are stimulated by tumor induced osteolytic factors (RANKL expression, Parathyroid hormone-related protein, Interleukin-6, matrix metalloproteinases and cathepsins). These factors induce (amongst others) the degradation of extracellular matrix and mineralized bone and increased invasion and migration of tumor cells [59].

The increased blood flow velocity of Du145 tumors, which was considerably greater than that of other cell lines and tissues, may have further contributed to this phenomenon because of impaired substrate exchange. The steady growth of Du145 tumors with high engraftment rates in bone and striated muscle could be used in subsequent studies to compare the effects of treatments for prostate cancer metastasis in both tissues.

\section{Conclusion}

This preclinical model of prostate cancer provided insight into organ-related microcirculation and its possible impact on tumor growth in bone and striated muscle. Monitoring the in vivo responses of the tumor and microcirculation to new therapeutic agents may help elucidate the dependence of prostate cancer bone metastases on the microenvironment and contribute to the development of organ-optimized therapies.

\section{Additional files}

Additional file 1: Figure S1. Three locations of interest within the Du145 tumor cells in soft tissue over observation period measured with intravital fluorescence microscope and a 20x objective. (TIF 368 kb) 
Additional file 2: Figure S2. Three locations of interest within the $\mathrm{PC}$ tumor cells in bone over observation period measured with intravital fluorescence microscope and a 20x objective. (TIF $287 \mathrm{~kb}$ )

Additional file 3: Table S1. Microcirculatory parameters and tumor growth in the femur window (FW) and dorsal skinfold chamber (DSC) during the observation period. (DOCX $33 \mathrm{~kb}$ )

\section{Abbreviations}

BFR: Blood flow rate; D: Mean diameters; DSC: Dorsal skinfold chamber; FW: Femur window; HT: Average hematocrit; NSG: Non-obese diabetic/ severe combined immunodeficiency/y-chain; PERM: Permeability; TPR: Tissue perfusion rate; VD: Vessel density; Vmean: Centerline velocity

\section{Acknowledgments}

We would like to thank the members of the Department of Oncology, Hematology and Bone Marrow Transplantation with Section Pneumology, Hubertus Wald University Cancer Centre, Hamburg-Eppendorf, for kindly providing the tumor cell lines.

\section{Funding}

The study was supported in part by the Hamburg foundation for sponsorship of cancer treatment grant number 1314/100. The funding body had no impact on the design of the study and collection, analysis, and interpretation of data and also no impact on drafting of the manuscript.

\section{Availability of data and materials}

The data used during the current study are available from the corresponding author on reasonable request.

\section{Authors' contributions}

JW conducted the cell biology and molecular biology experiments. HM, LV, SH, JS performed experiments. SH and JS supported animal feeding. HM, LV and MS analyzed results. MS and KK performed statistical analysis. CS, MS and LV designed the whole experiments. HM and LV wrote the paper. MS, CS, KK and JW edited the manuscript. All authors contributed to revise the manuscript and approved the final version for publication.

\section{Ethics approval and consent to participate}

The study was approved by the local governmental animal care committee (protocol number 05/12) and was conducted in accordance with the German legislation on the protection of animals and the National Institutes of Health (NIH) Guidelines for Care and Use of Laboratory Animals (NIH Publication \#85-23 Rev. 1985). An ethics approval for the use of the cell lines was not necessary.

\section{Consent for publication}

Not applicable

\section{Competing interests}

The authors declare that they have no competing interests.

\section{Publisher's Note}

Springer Nature remains neutral with regard to jurisdictional claims in published maps and institutional affiliations.

\footnotetext{
Author details

${ }^{1}$ Department of Orthopaedic Surgery, University Medical Center Hamburg-Eppendorf, 20246 Hamburg, Germany. ²Department of Trauma, Orthopaedic, and Plastic Surgery, University Medical Center Goettingen, Goettingen, Germany. ${ }^{3}$ Department of Spine Surgery, Klinikum Bad Bramstedt, 24576 Bad Bramstedt, Germany. ${ }^{4}$ Department of Hematology, Oncology and Stem Cell Transplantation with Section Pneumology, University Medical Center Hamburg-Eppendorf, 20246 Hamburg, Germany. ${ }^{5}$ Center of Psychosocial Medicine, Institute and Policlinics of Medical Psychology, University Medical Center Hamburg-Eppendorf, 20246 Hamburg, Germany.
}

Received: 20 December 2017 Accepted: 5 October 2018 Published online: 16 October 2018

\section{References}

1. Jemal A, Fedewa SA, Ma J, Siegel R, Lin CC, Brawley O, et al. Prostate Cancer incidence and PSA testing patterns in relation to USPSTF screening recommendations. JAMA 2015;314(19):2054-2061. https://doi.org/10.1001/ jama.2015.14905. PubMed PMID: 26575061.

2. Wang N, Docherty FE, Brown HK, Reeves KJ, Fowles AC, Ottewell PD, et al. Prostate cancer cells preferentially home to osteoblast-rich areas in the early stages of bone metastasis: evidence from in vivo models. J Bone Miner Res 2014;29(12):2688-2696. https://doi.org/10.1002/jbmr.2300. PubMed PMID: 24956445.

3. Keyes KA, Mann L, Teicher B, Alvarez E. Site-dependent angiogenic cytokine production in human tumor xenografts. Cytokine 2003;21(2):98-104. PubMed PMID: 12670449.

4. Fukumura D, Duda DG, Munn LL, Jain RK. Tumor microvasculature and microenvironment: novel insights through intravital imaging in pre-clinical models. Microcirculation. 2010;17(3):206-225. https://doi.org/10.1111/j.15498719.2010.00029.x. PubMed PMID: 20374484; PubMed Central PMCID: PMCPMC2859831.

5. Reeves KJ, Hurrell JE, Cecchini M, van der Pluijm G, Down JM, Eaton CL, et al. Prostate cancer cells home to bone using a novel in vivo model: modulation by the integrin antagonist GLPG0187. Int J Cancer 2015;136(7): 1731-1740. https://doi.org/10.1002/ijc.29165. PubMed PMID: 25156971.

6. Shen MM, Abate-Shen C. Molecular genetics of prostate cancer: new prospects for old challenges. Genes Dev. 2010;24(18):1967-2000. https://doi. org/10.1101/gad.1965810. PubMed PMID: 20844012; PubMed Central PMCID: PMCPMC2939361.

7. Hansen-Algenstaedt N, Schaefer C, Wolfram L, Joscheck C, Schroeder M, Algenstaedt $P$, et al. Femur window--a new approach to microcirculation of living bone in situ. J Orthop Res 2005;23(5):1073-1082. https://doi.org/10. 1016/j.orthres.2005.02.013. PubMed PMID: 15890486.

8. Lee IJ, Lee EJ, Park H, Kim W, Ha SJ, Shin YK, et al. Altered Biological Potential and Radioresponse of Murine Tumors in Different Microenvironments. Cancer Res Treat. 2016;48(2):727-737. https://doi.org/10.4143/crt.2014.350. PubMed PMID: 26323643: PubMed Central PMCID: PMCPMC4843754.

9. Gu B, Espana L, Mendez O, Torregrosa A, Sierra A. Organ-selective chemoresistance in metastasis from human breast cancer cells: inhibition of apoptosis, genetic variability and microenvironment at the metastatic focus. Carcinogenesis 2004;25(12):2293-2301. https://doi.org/10.1093/carcin/ bgh272. PubMed PMID: 15347599.

10. Monsky WL, Mouta Carreira C, Tsuzuki Y, Gohongi T, Fukumura D, Jain RK. Role of host microenvironment in angiogenesis and microvascular functions in human breast cancer xenografts: mammary fat pad versus cranial tumors. Clin Cancer Res 2002:8(4):1008-1013. PubMed PMID: 11948107.

11. Jung YD, Ahmad SA, Akagi Y, Takahashi Y, Liu W, Reinmuth N, et al. Role of the tumor microenvironment in mediating response to anti-angiogenic therapy. Cancer Metastasis Rev 2000;19(1-2):147-157. PubMed PMID: 11191054.

12. Gohongi T, Fukumura D, Boucher $Y$, Yun CO, Soff GA, Compton $C$, et al. Tumor-host interactions in the gallbladder suppress distal angiogenesis and tumor growth: involvement of transforming growth factor beta1. Nat Med 1999:5(10):1203-1208. PubMed PMID: 10502827

13. Yuan F, Salehi HA, Boucher Y, Vasthare US, Tuma RF, Jain RK. Vascular permeability and microcirculation of gliomas and mammary carcinomas transplanted in rat and mouse cranial windows. Cancer Res. 1994;54(17):4564-8.

14. Schaefer C, Fuhrhop I, Schroeder M, Viezens L, Otten J, Fiedler W, et al. Microcirculation of secondary bone tumors in vivo: the impact of minor surgery at a distal site. J Orthop Res 2010;28(11):1515-1521. https://doi.org/ 10.1002/jor.21166. PubMed PMID: 20872590

15. Schaefer C, Schroeder M, Fuhrhop I, Viezens L, Otten J, Fiedler W, et al. Primary tumor dependent inhibition of tumor growth, angiogenesis, and perfusion of secondary breast cancer in bone. J Orthop Res 2011;29(8): 1251-1258. https://doi.org/10.1002/jor.21402. PubMed PMID: 21381098.

16. Fuhrhop I, Schroeder M, Rafnsdottir SL, Viezens L, Ruther W, HansenAlgenstaedt $\mathrm{N}$, et al. Dynamics of microvascular remodelling during tumor growth in bone. J Orthop Res 2010;28(1):27-31. PubMed PMID: 19642113.

17. Menger MD, Laschke MW, Vollmar B. Viewing the microcirculation through the window: some twenty years experience with the hamster dorsal skinfold chamber. Eur Surg Res. 2002:34(1-2):83-91. doi: 48893. PubMed PMID: 11867907. 
18. Yuan F, Leunig M, Berk DA, Jain RK. Microvascular permeability of albumin, vascular surface area, and vascular volume measured in human adenocarcinoma LS174T using dorsal chamber in SCID mice. Microvasc Res. 1993:45(3):269-89.

19. Hansen-Algenstaedt N, Joscheck C, Schaefer C, Lamszus K, Wolfram L, Biermann T, et al. Long-term observation reveals time-course-dependent characteristics of tumour vascularisation. Eur J Cancer 2005;41(7):1073-1085. https://doi.org/10.1016/j.ejca.2004.12.034. PubMed PMID: 15862758.

20. Brizel DM, Klitzman B, Cook JM, Edwards J, Rosner G, Dewhirst MW. A comparison of tumor and normal tissue microvascular hematocrits and red cell fluxes in a rat window chamber model. Int J Radiat Oncol Biol Phys. 1993;25(2):269-76.

21. Yuan F, Leunig M, Huang SK, Berk DA, Papahadjopoulos D, Jain RK. Microvascular permeability and interstitial penetration of sterically stabilized (stealth) liposomes in a human tumor xenograft. Cancer Res 1994;54(13): 3352-3356. PubMed PMID: 8012948.

22. Simmons JK, Hildreth BE, 3rd, Supsavhad W, Elshafae SM, Hassan BB, Dirksen WP, et al. Animal Models of Bone Metastasis. Vet Pathol. 2015;52(5):827-841. https://doi.org/10.1177/0300985815586223. PubMed PMID: 26021553; PubMed Central PMCID: PMCPMC4545712.

23. Simpson-Abelson MR, Sonnenberg GF, Takita H, Yokota SJ, Conway TF, Jr., Kelleher RJ, Jr., et al. Long-term engraftment and expansion of tumorderived memory $T$ cells following the implantation of non-disrupted pieces of human lung tumor into NOD-scid IL2Rgamma(null) mice. J Immunol 2008:180(10):7009-7018. PubMed PMID: 18453623.

24. Roth MD, Harui A. Human tumor infiltrating lymphocytes cooperatively regulate prostate tumor growth in a humanized mouse model. J Immunother Cancer. 2015;3:12. https://doi.org/10.1186/s40425-015-0056-2. PubMed PMID: 25901284; PubMed Central PMCID: PMCPMC4404579.

25. Broderick L, Yokota SJ, Reineke J, Mathiowitz E, Stewart CC, Barcos M, et al. Human CD4+ effector memory T cells persisting in the microenvironment of lung cancer xenografts are activated by local delivery of IL-12 to proliferate, produce IFN-gamma, and eradicate tumor cells. J Immunol 2005; 174(2):898-906. PubMed PMID: 15634912.

26. Ampuja M, Alarmo EL, Owens P, Havunen R, Gorska AE, Moses HL, et al. The impact of bone morphogenetic protein 4 (BMP4) on breast cancer metastasis in a mouse xenograft model. Cancer Lett 2016;375(2):238-244. https://doi.org/10.1016/j.canlet.2016.03.008. PubMed PMID: 26970275.

27. Pienta KJ, Abate-Shen C, Agus DB, Attar RM, Chung LW, Greenberg NM, et al. The current state of preclinical prostate cancer animal models. Prostate. 2008;68(6):629-639. https://doi.org/10.1002/pros.20726. PubMed PMID: 18213636; PubMed Central PMCID: PMCPMC3681409.

28. Kai L, Wang J, Ivanovic M, Chung YT, Laskin WB, Schulze-Hoepfner F, et al. Targeting prostate cancer angiogenesis through metastasis-associated protein 1 (MTA1). Prostate 2011;71(3):268-280. https://doi.org/10.1002/pros. 21240. PubMed PMID: 20717904.

29. Thibaudeau L, Taubenberger AV, Holzapfel BM, Quent VM, Fuehrmann T, Hesami $P$, et al. A tissue-engineered humanized xenograft model of human breast cancer metastasis to bone. Dis Model Mech. 2014;7(2):299-309. https://doi.org/10.1242/dmm.014076. PubMed PMID: 24713276; PubMed Central PMCID: PMCPMC3917251.

30. Bauerle T, Komljenovic D, Berger MR, Semmler W. Multi-modal imaging of angiogenesis in a nude rat model of breast cancer bone metastasis using magnetic resonance imaging, volumetric computed tomography and ultrasound. J Vis Exp. 2012;(66):e4178. https://doi.org/10.3791/4178. PubMed PMID: 22929330; PubMed Central PMCID: PMCPMC3486767.

31. Weissleder R. Scaling down imaging: molecular mapping of cancer in mice. Nat Rev Cancer 2002;2(1):11-18. https://doi.org/10.1038/nrc701. PubMed PMID: 11902581

32. Fukumura D, Yuan F, Monsky WL, Chen Y, Jain RK. Effect of host microenvironment on the microcirculation of human colon adenocarcinoma. Am J Pathol 1997;151(3):679-688. PubMed PMID: 9284816.

33. Sewell IA. Studies of the microcirculation using transparent tissue observation chambers inserted in the hamster cheek pouch. J Anat 1966; 100(4):839-856. PubMed PMID: 5969981

34. Jain RK, Munn L, Fukumura D. Dissecting tumor pathophysiology using Intravital microscopy. Nature Review Cancer. 2002;2:266-76.

35. Chambers AF, Groom AC, MacDonald IC. Dissemination and growth of cancer cells in metastatic sites. Nat Rev Cancer 2002;2(8):563-572. PubMed PMID: 12154349

36. Wang Y, Revelo MP, Sudilovsky D, Cao M, Chen WG, Goetz L, et al. Development and characterization of efficient xenograft models for benign and malignant human prostate tissue. Prostate 2005;64(2):149-159. https://doi.org/10.1002/pros. 20225. PubMed PMID: 15678503.

37. Price JE, Polyzos A, Zhang RD, Daniels LM. Tumorigenicity and metastasis of human breast carcinoma cell lines in nude mice. Cancer Res 1990;50(3):717721. PubMed PMID: 2297709.

38. Buijs JT, van der Pluijm G. Osteotropic cancers: from primary tumor to bone. Cancer Lett 2009;273(2):177-193. https://doi.org/10.1016/j.canlet.2008.05.044. PubMed PMID: 18632203.

39. Holmgren L, O'Reilly MS, Folkman J. Dormancy of micrometastases: balanced proliferation and apoptosis in the presence of angiogenesis suppression. Nat Med 1995;1(2):149-153. PubMed PMID: 7585012

40. Gimbrone MA, Jr., Cotran RS, Leapman SB, Folkman J. Tumor growth and neovascularization: an experimental model using the rabbit cornea. J Natl Cancer Inst 1974;52(2):413-427. PubMed PMID: 4816003.

41. Agliano A, Martin-Padura I, Mancuso P, Marighetti P, Rabascio C, Pruneri G, et al. Human acute leukemia cells injected in NOD/LtSz-scid/IL-2Rgamma null mice generate a faster and more efficient disease compared to other NOD/scid-related strains. Int J Cancer 2008;123(9):2222-2227. https://doi. org/10.1002/ijc.23772. PubMed PMID: 18688847.

42. Pazzaglia UE, Congiu T, Raspanti M, Ranchetti F, Quacci D. Anatomy of the intracortical canal system: scanning electron microscopy study in rabbit femur. Clin Orthop Relat Res. 2009;467(9):2446-2456. https://doi.org/10. 1007/s11999-009-0806-x. PubMed PMID: 19330389; PubMed Central PMCID: PMCPMC2866945

43. Weiland AJ, Berggren A, Jones L. The acute effects of blocking medullary blood supply on regional cortical blood flow in canine ribs as measured by the hydrogen washout technique. Clin Orthop Relat Res 1982;(165):265-272. PubMed PMID: 7075070

44. Sottnik JL, Zhang J, Macoska JA, Keller ET. The PCa Tumor Microenvironment Cancer Microenviron. 2011;4(3):283-297. https://doi.org/10.1007/s12307-0110073-8. PubMed PMID: 21728070; PubMed Central PMCID: PMCPMC3234329.

45. Nemeth JA, Harb JF, Barroso U, Jr., He Z, Grignon DJ, Cher ML. Severe combined immunodeficient-hu model of human prostate cancer metastasis to human bone. Cancer Res 1999:59(8):1987-1993. PubMed PMID: 10213511.

46. Folkman J. Tumor angiogenesis: therapeutic implications. N Engl J Med 1971;285(21):1182-1186. PubMed PMID: 4938153.

47. Griffon-Etienne G, Boucher Y, Brekken C, Suit HD, Jain RK. Taxane-induced apoptosis decompresses blood vessels and lowers interstitial fluid pressure in solid tumors: clinical implications. Cancer Res 1999;59(15):3776-3782. PubMed PMID: 10446995.

48. Schaefer C, Krause M, Fuhrhop I, Schroeder M, Algenstaedt P, Fiedler W, et al. Time-course-dependent microvascular alterations in a model of myeloid leukemia in vivo. Leukemia 2008;22(1):59-65. PubMed PMID: 17898789.

49. Patan S. Vasculogenesis and angiogenesis. Cancer Treat Res 2004;117:3-32 PubMed PMID: 15015550.

50. Dvorak HF, Detmar M, Claffey KP, Nagy JA, van de Water L, Senger DR. Vascular permeability factor/vascular endothelial growth factor: an important mediator of angiogenesis in malignancy and inflammation. Int Arch Allergy Immunol 1995;107(1-3):233-235. PubMed PMID: 7542074.

51. Fidler IJ. Critical determinants of metastasis. Semin Cancer Biol 2002;12(2): 89-96. https://doi.org/10.1006/scbi.2001.0416. PubMed PMID: 12027580.

52. Pietras K, Ostman A, Sjoquist M, Buchdunger E, Reed RK, Heldin CH, et al. Inhibition of platelet-derived growth factor receptors reduces interstitial hypertension and increases transcapillary transport in tumors. Cancer Res 2001;61(7):2929-2934. PubMed PMID: 11306470.

53. Dvorak HF, Detmar M, Claffey KP, Nagy JA, van de Water L, Senger DR. Vascular permeability factor/vascular endothelial growth factor: an important mediator of angiogenesis in malignancy and inflammation. [review] [18 refs]. International Archives of Allergy \& Immunology. 1995: 107(1-3):233-5.

54. Chung LW, Baseman A, Assikis V, Zhau HE. Molecular insights into prostate cancer progression: the missing link of tumor microenvironment. J Urol 2005;173(1):10-20. https://doi.org/10.1097/01.ju.0000141582.15218.10. PubMed PMID: 15592017

55. Hlatky L, Hahnfeldt P, Folkman J. Clinical application of antiangiogenic therapy: microvessel density, what it does and Doesn't tell us. JNCl Cancer Spectrum. 2002;94(12):883-93.

56. Mussawy H, Viezens L, Hauenherm G, Schroeder M, Schaefer C. In vivo functional and morphological characterization of bone and striated muscle microcirculation in NSG mice. PLoS One 2017:12(8):e0183186. https://doi. org/10.1371/journal.pone.0183186. PubMed PMID: 28800593. 
57. Virk MS, Alaee F, Petrigliano FA, Sugiyama O, Chatziioannou AF, Stout D, et al. Combined inhibition of the BMP pathway and the RANKRANKL axis in a mixed lytic/blastic prostate cancer lesion. Bone. 2011; 48(3):578-587. https://doi.org/10.1016/j.bone.2010.11.003. PubMed PMID: 21073986; PubMed Central PMCID: PMCPMC3039095.

58. Sottnik JL, Dai J, Zhang H, Campbell B, Keller ET. Tumor-induced pressure in the bone microenvironment causes osteocytes to promote the growth of prostate cancer bone metastases. Cancer Res. 2015;75(11):2151-2158. https://doi.org/10.1158/0008-5472.CAN-14-2493. PubMed PMID: 25855383; PubMed Central PMCID: PMCPMC4452392.

59. Sottnik JL, Keller ET. Understanding and targeting osteoclastic activity in prostate cancer bone metastases. Curr Mol Med. 2013;13(4):626-639. PubMed PMID: 23061677; PubMed Central PMCID: PMCPMC3624036.

Ready to submit your research? Choose BMC and benefit from:

- fast, convenient online submission

- thorough peer review by experienced researchers in your field

- rapid publication on acceptance

- support for research data, including large and complex data types

- gold Open Access which fosters wider collaboration and increased citations

- maximum visibility for your research: over $100 \mathrm{M}$ website views per year

At $\mathrm{BMC}$, research is always in progress.

Learn more biomedcentral.com/submissions 